\title{
Further Studies on Germination of Sporangiospores of Rhizopus arrhizus
}

\author{
BY J. A. EKUNDAYO* \\ Department of Botany, University of Bristol
}

(Received 6 July 1965)

\begin{abstract}
SUMMARY
Although sporangiospores of Rhizopus arrhizus do not swell or produce germ-tubes in distilled water, when they are suspended in heavy water the water in the spore is exchanged with heavy water in the medium. Spores swell and some produce germ-tubes in a glucose solution. Maximum germination occurred in the presence of utilizable carbon and nitrogen sources and suitable compounds containing phosphate, sulphate, potassium and magnesium ions. Germination was accompanied by a considerable increase in oxygen uptake and by the time the germ-tube emerged, the dry weight had increased by about $500 \%$. Respiratory inhibitors (2,41-dinitrophenol, sodium azide, potassium cyanide) inhibited germination; sodium azide inhibited both the oxygen uptake and the dry weight increase.

Electron microscope studies showed structural changes in germinating Rhizopus arrhizus spores similar to those reported in other Rhizopus species: a new inner wall layer was formed, and changes in form and probably number of mitochondria occur. The effects of either anaerobic conditions or media containing sodium azide, on fine structure of germinating $\boldsymbol{R}$. arrhizus spores were similar; mitochondrial multiplication ceases, mitochondrial cristae became a disorganized collection of undulating 'plates', and the nuclear membrane became split in places, thus giving rise to small vacuoles between the two electron-dense layers of the membrane.
\end{abstract}

\section{INTRODUCTION}

Some aspects of the physiology of germination of sporangiospores of Rhizopus arrhizus Fischer have already been reported by Ekundayo \& Carlile (1964), who found that initiation of germination required the presence of glucose or fructose; maximum germination required in addition a nitrogen source, $\mathrm{PO}_{4}{ }^{3-}$ and $\mathrm{K}^{+}$or $\mathrm{Na}^{+}$. On media containing these nutrients, the spore increased in length from 5.5 to 13.5 $\mu$ in $8 \mathrm{hr}$. Anaerobic conditions inhibited germination. Weber \& Ogawa (1965) observed that only proline, in the absence of phosphate, stimulated germination of $\boldsymbol{R}$. arrhizus spores among the individual amino acids, sugars, organic acids, vitamins and inorganic nitrogen sources tested in their studies. Hawker \& Abbott $(1963 b)$ described changes in fine structure during germination of sporangiospores of $\boldsymbol{R}$. nigricans ( $=\boldsymbol{R}$. stolonifer) and $\boldsymbol{R}$. sexualis. Washed spores of these species also failed to germinate in distilled water (Abbott, personal communication). The present investigations extended these various lines of study.

\footnotetext{
* Present address: Department of Biology, University of Lagos, Nigeria.
} 


\section{METHODS}

General. The preparation of media and inocula and the assessment of spore germination were as previously described (Ekundayo \& Carlile, 1964).

Permeability studies with heavy water (deuterium oxide) as tracer. Spores, filtered, centrifuged and dried over $\mathrm{P}_{2} \mathrm{O}_{5}$ at 0.05 torr in an Edwards High Vacuum Unit, were suspended in $1 \mathrm{ml}$. $\mathrm{D}_{2} \mathrm{O}$ in a centrifuge tube covered with aluminium foil and incubated at $30^{\circ}$ for $18 \mathrm{hr}$. The $\mathrm{D}_{2} \mathrm{O}$ was decanted and distilled under reduced pressure in a micro-distillation apparatus. The density of the distillate was determined by the gradient tube method (Shaw, 1955). $50 \mathrm{ml} . \mathrm{CCl}_{4}$ were put in a $100 \mathrm{ml}$. graduated cylinder, $50 \mathrm{ml}$. Kerosene were added to the top of the carbon tetrachloride, and the interface between them was stirred and allowed to stand for $24 \mathrm{hr}$ in a water-bath at $20^{\circ}$ to allow the density gradient to become established. The density of $\mathrm{D}_{2} \mathrm{O}$ was calibrated by introducing drops of known concentrations of $\mathrm{D}_{2} \mathrm{O}$ into the $\mathrm{CCl}_{4}+$ Kerosene mixture and measuring the positions of the drops with a travelling microscope and vernier. Drops of the distillate were then added, their equilibrium position determined and the equivalent $\mathrm{D}_{2} \mathrm{O}$ concentration was read from the calibration graph. The percentage exchange was taken as the difference between the percentage of $\mathrm{D}_{2} \mathrm{O}$ in the distillate from spore suspension and from $100 \% \mathrm{D}_{2} \mathrm{O}$ control. The theoretical full exchange value was derived from the equation:

$$
\% \text { full exchange }=\frac{x}{x+y} \times 100,
$$

where $x=$ wt. (mg.) of water from spore sample at $100^{\circ}$ for $24 \mathrm{hr}$;

$y=$ wt. (mg.) of $1 \mathrm{ml} . \mathrm{D}_{2} \mathrm{O}$ at room temperature.

Electron microscopy. Ungerminated Rhizopus spores were not always well fixed after $24 \mathrm{hr}$ in $2 \% \mathrm{KMnO}_{4}$, glutaraldehyde or osmic tetroxide. Satisfactory fixation was achieved by shaking the spore suspension in $4 \% \mathrm{KMnO}_{4}$ in veronal

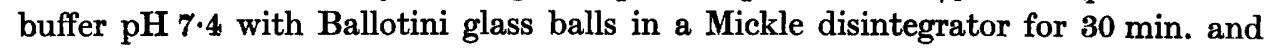
leaving the spores in the fixative at room temperature for a further $3 \frac{1}{2} \mathrm{hr}$. The spore suspension was then centrifuged at $2000 \mathrm{rev} . / \mathrm{min}$. for $5 \mathrm{~min}$. to separate the glass balls. The supernatant was decanted and centrifuged at $4000 \mathrm{rev} . / \mathrm{min}$. for $15 \mathrm{~min}$. and the spore deposit washed with distilled water. Only broken or damaged spores subsequently showed internal structure; it was, therefore, assumed that the fixative penetrated through the cracks in the walls.

Germinated spores were fixed with $2 \% \mathrm{KMnO}_{4}$ in veronal buffer $\mathrm{pH} \% \cdot 4$ (Luft, 1956) for $4 \mathrm{hr}$ at room temperature.

After fixation the spores were dehydrated with acetone, embedded in vestopal $W$, sectioned, and observed with either an Akashi TRS-50 or a Siemens Elmiskop I electron microscope.

\section{RESULTS}

\section{Permeability of Rhizopus arrhizus spores}

Ekundayo \& Carlile (1964) showed that $R$. arrhizus spores did not swell or produce germ-tubes in sterile distilled water; maximum swelling and germ-tube production by all spores required the presence of utilizable carbon and nitrogen sources and compounds containing phosphate, potassium or sodium ions. 
In the present studies, wetting the spores with Gemex Z-11, Manoxol OT, Nonidet $\mathbf{P 4 2}$ or Teepol either before or during their incubation in water did not make them swell or produce germ-tubes in water.

Experiments in which spores were suspended in solutions of the standard medium containing high concentrations of $\left(\mathrm{NH}_{4}\right)_{2} \mathrm{SO}_{4}$ showed that saturated solutions of $\left(\mathrm{NH}_{4}\right)_{2} \mathrm{SO}_{4}$ did not plasmolyse ungerminated Rhizopus arrhizus spores. Spores which had been incubated for about $3 \mathrm{hr}$ on the standard medium were, however, plasmolysed by standard medium containing $3 \cdot 0 \mathrm{M}-\left(\mathrm{NH}_{4}\right)_{2} \mathrm{SO}_{4}$.

Heavy water was used as a tracer to find whether ungerminated Rhizopus arrhizus spores could exchange the water in the spore with heavy water in the medium. The results are given in Table 1. Experimental values were higher than theoretical figures obtained by the use of the equation given under Methods; full exchange values were always obtained. This suggests that $\boldsymbol{R}$. arrhizus spores are permeable to water even though they do not swell in it in the absence of suitable nutrients.

Vacuum-dried spores did not swell or produce germ-tubes in distilled water; but all the spores germinated in the standard medium. The ability of the spores to exchange their water with the heavy water in the medium, demonstrated above, was therefore not due to an effect of drying on the permeability of the spore wall.

Table 1. The estimation of heavy water (deuterium oxide) in permeability studies with Rhizopus arrhizus spores

\begin{tabular}{|c|c|c|c|c|}
\hline $\begin{array}{l}\text { Wt. (mg.) of } \\
\text { vacuum-dried } \\
\text { spores }\end{array}$ & $\begin{array}{l}\text { Wt. (mg.) of } \\
\text { oven-dried } \\
\text { spores }\end{array}$ & $\begin{array}{c}\text { Wt. (mg.) of } \\
\text { water in spores } \\
=\frac{\% \text { water } \times \mathbf{M}}{100}\end{array}$ & $\begin{array}{c}\text { Theoretical } \\
\text { full-exchange } \\
\text { value }(\%)\end{array}$ & $\begin{array}{c}\text { Experimental } \\
\text { exchange } \\
\text { value }(\%)\end{array}$ \\
\hline $389 \cdot 3$ & $282 \cdot 0$ & $107 \cdot 4$ & $9 \cdot 7$ & $15 \cdot 4$ \\
\hline 296.9 & $167 \cdot 1$ & $129 \cdot 8$ & $11 \cdot 5$ & $17 \cdot 8$ \\
\hline
\end{tabular}

Table 2. The effect of respiratory inhibitors on germination of Rhizopus arrhizus on standard medium at $30^{\circ}$

\begin{tabular}{|c|c|c|c|c|}
\hline $\begin{array}{c}\text { Chemical inhibitor } \\
\text { in medium }\end{array}$ & $\begin{array}{c}\text { Least molar } \\
\text { concentration } \\
\text { inhibiting } \\
\text { germination }\end{array}$ & $\begin{array}{c}\text { Average spore } \\
\text { diameter }(\mu) \\
\text { time } 0\end{array}$ & $\begin{array}{c}\text { Average spore } \\
\text { diameter }(\mu) \\
\text { at } 8 \mathbf{h r}\end{array}$ & $\begin{array}{l}\text { Spores (\%) } \\
\text { with germ- } \\
\text { tubes at } 8 \mathrm{hr}\end{array}$ \\
\hline 2,4-Dinitrophenol & $5 \times 10^{-3}$ & $\mathbf{5 \cdot 5}$ & $6 \cdot 0$ & 15 \\
\hline Sodium azide & $10^{-3}$ & $\mathbf{5 \cdot 5}$ & $5 \cdot 5$ & 5 \\
\hline Potassium cyanide & $5 \times 10^{-3}$ & $5 \cdot 5$ & $8 \cdot 0$ & 30 \\
\hline
\end{tabular}

Effect of respiratory inhibitors on spore germination

Mandels \& Darby (1953) reported the inhibition by sodium azide of spore swelling in Myrothecium verrucaria in the basal nutrient medium.

The effect of 2,4-dinitrophenol, sodium azide and potassium cyanide on the germination of Rhizopus arrhizus spores was, therefore, investigated. A decimolar solution of each inhibitor in liquid standard medium was made and samples of it were withdrawn into different Petri dishes. Melted standard medium agar was added to each Petri dish to a total volume of $20 \mathrm{ml}$. and allowed to solidify. Four sterile cellophan strips were placed on the solidified medium in each Petri dish 
and two drops of spore suspension were spread on each strip. After $8 \mathrm{hr}$ the least concentration of each inhibitor causing incomplete swelling and/or less than $50 \%$ germ-tube production was determined. 2,4-Dinitrophenol, sodium azide and potassium cyanide concentrations up to about $10^{-3} \mathrm{M}$ inhibited both spore swelling and germ-tube emergence in $R$. arrhizus (Table 2).

\section{Effect of $10^{-3} M-N_{3} N_{3}$ on germinating Rhizopus arrhizus spores}

Experiments in which ungerminated spores were placed in contact with the inhibitor for different periods, after which they were transferred to fresh media not containing the inhibitor, showed that $R$. arrhizus spores on the standard medium containing $5 \times 10^{-3} \mathrm{M}-\mathrm{NaN}_{3}$ remained unswollen and without germ-tubes for at least $24 \mathrm{hr}$, but if then transferred to the standard medium not containing the inhibitor, all spores swelled and produced germ-tubes after a further $8 \mathrm{hr}$. The effect of the inhibitor on the ungerminated spore was, therefore, not permanent.

The following experiment was accordingly made to investigate the effect of $10^{-3}$ $\mathrm{M}-\mathrm{NaN}_{3}$ on spores which had been incubated for $3 \mathrm{hr}$ on the standard medium. Such partially swollen spores were transferred either to the standard medium containing $10^{-3} \mathrm{M}-\mathrm{NaN}_{3}$ or to water agar (with or without $10^{-3} \mathrm{M}-\mathrm{NaN}_{3}$ ) for $5 \mathrm{hr}$. The results are given in Table 3. Spores transferred to the standard medium containing $10^{-3} \mathrm{M}-\mathrm{NaN}_{3}$ did not swell further or produce germ-tubes, but spores transferred to water agar, with or without the inhibitor, produced germ-tubes but stopped swelling. This suggested that $\mathrm{NaN}_{3}$ was taken into the spores only when utilisable exogenous nutrients were present.

Table 3. Effect of $10^{-3} \mathrm{M}-\mathrm{NaN}$ on germinating Rhizopus arrhizus spores at $30^{\circ}$

\begin{tabular}{|c|c|c|c|c|}
\hline \multicolumn{5}{|c|}{ arrhizus spores at $30^{\circ}$} \\
\hline & \multicolumn{2}{|c|}{$\begin{array}{l}\text { Condition at time of } \\
\text { transfer }(3 \mathrm{hr})\end{array}$} & \multicolumn{2}{|c|}{ Condition at $8 \mathrm{hr}$} \\
\hline Treatment & $\begin{array}{c}\text { Average } \\
\text { spore } \\
\text { diam. }(\mu)\end{array}$ & $\begin{array}{c}\text { Spores }(\%) \\
\text { with } \\
\text { germ-tubes }\end{array}$ & $\begin{array}{l}\text { Average } \\
\text { spore } \\
\text { diam. }(\mu)\end{array}$ & $\begin{array}{c}\text { Spores (\%) } \\
\text { with } \\
\text { germ-tubes }\end{array}$ \\
\hline $\begin{array}{l}3 \mathrm{hr} \text { on standard medium, then: } \\
5 \mathrm{hr} \text { on medium }+10^{-3} \mathrm{M}-\mathrm{NaN}_{3}\end{array}$ & 7.5 & 0 & 8.0 & 0 \\
\hline $5 \mathrm{hr}$ on water agar $+10^{-8} \mathrm{M}-\mathrm{NaN}_{3}$ & $7 \cdot 5$ & $\mathbf{0}$ & $7 \cdot 5$ & 90 \\
\hline $5 \mathrm{hr}$ on water agar & $7 \cdot 5$ & $\mathbf{0}$ & $8 \cdot 0$ & 100 \\
\hline 5 hr on fresh standard medium & $7 \cdot 5$ & $\mathbf{0}$ & 13.5 & 100 \\
\hline All $8 \mathrm{hr}$ on standard medium & - & - & $13 \cdot 5$ & 100 \\
\hline All $8 \mathrm{hr}$ on plain agar & 一 & - & $5 \cdot 5$ & $\mathbf{0}$ \\
\hline
\end{tabular}

Dry weight changes during germination

Dry weight was determined at intervals during the germination of Rhizopus arrhizus spores in the standard medium with or without sodium azide. $25 \mathrm{ml}$. samples of spore suspension in water were measured into $150 \mathrm{ml}$. Erlenmeyer flasks containing either $25 \mathrm{ml}$. of double-strength standard medium with or without $10^{-3} \mathrm{M}-\mathrm{NaN}_{3}$ (to maintain the usual standard medium nutrient level on dilution with spore suspension), or $25 \mathrm{ml}$. of water. Four replicates of each treatment were set up. Air, filtered by passing through cotton wool plugs, was bubbled through the suspensions which were maintained at $30 \pm 1^{\circ}$. After $8 \mathrm{hr}$, the contents of 
similarly treated flasks were pooled and filtered through a sterile sintered crucible of fine porosity lined with sterile glass paper of known weight. Spores were washed with distilled water and then acetone, and dried at $100^{\circ}$ for $6 \mathrm{hr}$. A considerable increase (about $500 \%$ ) in dry weight accompanied the germination of $R$. arrhizus spores in the standard medium, but in the presence of $10^{-3} \mathrm{M}-\mathrm{NaN}_{3}$, no increase in dry weight occurred (Table 4).

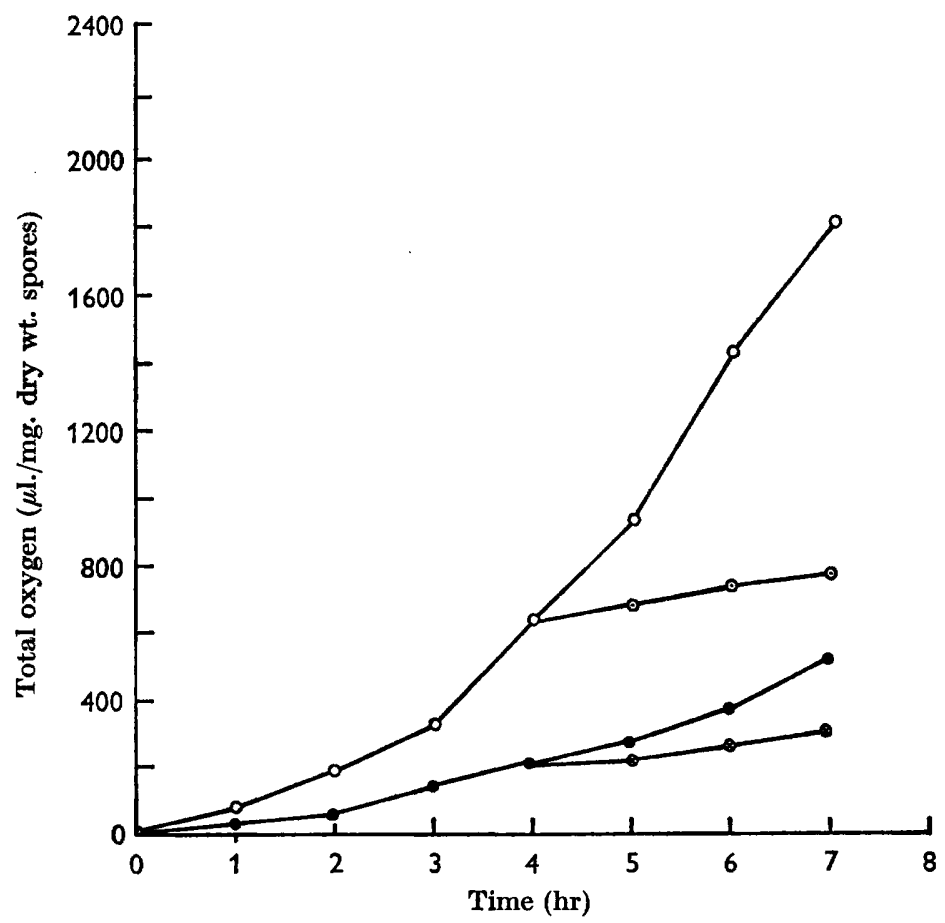

Fig. 1. Effect of sodium azide on oxygen uptake by Rhizopui arrhizus spores at $30^{\circ}$. $\mathrm{O}-\mathrm{O}$, standard medium; $-\bullet$, standard medium + sodium azide at time zero; $\odot-\odot$, standard medium + sodium azide at $4 \mathrm{hr} ; \otimes-\otimes$, distilled water.

Table 4. Dry weight changes during germination of $\boldsymbol{R}$. arrhizus spores

Treatment

Spores at time 0

Spores in sterile distilled water for $8 \mathrm{hr}$

Spores in standard medium for $8 \mathrm{hr}$

Spores in standard medium $+10^{-3} \mathrm{M}-\mathrm{NaN}_{3}$ for $8 \mathrm{hr}$

Spores on standard medium for $3 \mathrm{hr}$

Spores in standard medium far $3 \mathrm{hr}$, then $5 \mathrm{hr}$ in medium containing $10^{-3} \mathrm{M}-\mathrm{NaN}_{3}$
Weight (mg.) of spores

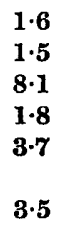

$3 \cdot 5$

\section{Respiration of Rhizopus arrhizus spores}

As it had been found that respiratory inhibitors (2,4-dinitrophenol, sodium azide, and potassium cyanide) inhibited germination of $\boldsymbol{R}$. arrhizus spores, the following experiments were made to investigate the dependence of spore germination on respiration. Measurements of oxygen uptake were made with Warburg 
respirometers (Umbreit, Burris \& Stauffer, 1957). The results are summarized in Fig. 1. Oxygen uptake by $R$. arrhizus spores in the standard medium was very high; in water, oxygen uptake was low and could be estimated only by using thick spore suspensions. $10^{-3} \mathrm{M}-\mathrm{NaN}_{3}$ inhibited oxygen uptake. Weber \& Ogawa (1965) observed that $10^{-3} \mathrm{M}-\mathrm{NaN}_{3}$ and $10^{-3} \mathrm{M}-\mathrm{NaF}$ completely inhibited oxygen uptake, whereas 2,4-dinitrophenol $\left(10^{-3} \mathrm{M}\right)$ stimulated respiration of $\boldsymbol{R}$. arrhizus spores in proline-phosphate mixtures.

\section{Electron microscope studies}

Hawker \& Abbott (1963b) studied the maturation and germination of sporangiospores of Rhizopus nigricans (R. stolonifer) and $\boldsymbol{R}$. sexualis. $\boldsymbol{R}$. arrhizus spores have been similarly studied; in Plate 1 , fig. 1 . can be seen changes in fine structure of germinating sporangiospores (on standard medium) similar to those observed by Hawker \& Abbott (1963b) in R. stolonifer. A new inner wall (IW) has been formed, and the large mitochondria (M) have occasional constrictions along the longer axis. Spores germinating on glucose agar contained similar structures, but no changes in spore fine structure were observed in spores on water agar.

Effect of sodium azide and anaerobic conditions on germinating spores. Rhizopus arrhizus spores which had been incubated on the standard medium for $\mathbf{3 ~ h r}$ and then transferred for $\mathbf{5} \mathrm{hr}$ either to standard medium in a sealed system filled with nitrogen or to standard medium containing $10^{-3} \mathrm{M}-\mathrm{NaN}_{3}$ usually stopped swelling and producing germ-tubes. Fine structure of the spores so treated, was, therefore, studied and it was found that mitochondrial division ceased, as shown by the large size of these organelles (Pls. 1, 2; figs. 2-4). Cristae which appeared as nearly parallel 'plates' in control spores became a disorderly collection of undulating plates (Pl. 2, figs. 3, 4). The nuclear membrane became split in places, thus giving rise to small vacuoles between the two electron-dense layers of the membrane. Gale \& McLain (1964) observed similar effects on spores of Candida albicans exposed to thiobenzoate; and Hirano \& Lindegren $(1961,1963)$ observed that mitochondria of Saccharomyces cerevisiae developed some abnormalities in partially anaerobic conditions, the mitochondrial cristae becoming replaced by a complex system of inner membranes. The finding that sodium azide and anaerobic conditions have similar effects on fine structure of $R$. arrhizus spores is interesting. If $\mathrm{NaN}_{3}$ inhibits spore germination by its inhibitory action on the cytochrome oxidasecytochrome c oxygen transfer system thus causing anaerobic conditions to occur (Stannard \& Horecker, 1948) it might be expected that anaerobic conditions would have the same effect as that of $\mathrm{NaN}_{3}$ on spore structure.

The microfibrillar structure of $R$. arrhizus cell-walls. Hawker \& Abbott (1963b) had observed that a thin inner wall consisting of tangentially arranged elements, resembling the wall of the vegetative hypha (Hawker \& Abbott, 1963a), but differing from the original spore wall, was laid down during germination of Rhizopus stolonifer and $\boldsymbol{R}$. sexualis spores.

A similar wall-layer was seen in germinating Rhizopus arrhizus spores. A comparative study of shadowed preparations of isolated cell walls of ungerminated and germinating spores and of young hyphae (about $16 \mathrm{hr}$ old) by Dawson's (1949) method showed that the microfibrils of $R$. arrhizus cell walls were oriented in a 
rather irregular and random fashion and no clear differences in microfibrillar structure of original spore walls, new inner spore walls and hyphal walls was detected.

\section{DISCUSSION}

The initiation of germination in Rhizopus arrhizus spores has been shown to require a utilizable carbon compound (Ekundayo \& Carlile, 1964). Earlier, it was thought that the metabolism of the carbon compound, probably at the spore surface, brought about induced permeability of the spore walls to mineral ions and water. Heavy water exchange experiments have since shown that $R$. arrhizus spores can exchange the water in the spore with heavy water in the medium in the absence of carbon compounds. This suggests that the spore is already permeable to water, and, probably, to mineral ions. Spore swelling, however, involves an increase in spore size and requires the spore wall to be extensible. Since swelling occurs on media containing utilisable carbon compounds (e.g. glucose) without any mineral salts, glucose is sufficient to induce the walls of $\boldsymbol{R}$. arrhizus spores to become more extensible.

Nickerson's (1963) work on yeast suggested an explanation of how glucose might bring about changes in the Rhizopus spore wall and thereby make it become extensible. Plasticity of the yeast wall was thought to result from a reduction of disulphide linkages in the protein component of the wall to sulphydryl groups, the ultimate reducing agent being $\mathrm{NADH}_{2}$ generated from glucose. If this theory applies to Rhizopus, a disulphide-containing protein complex must be present in the spore wall and the spore must contain enzyme systems capable of reducing disulphide linkages. Results of investigations by other workers support such a possibility: Crook \& Johnston (1962) demonstrated the presence of proteincarbohydrate complexes in a wide range of fungal cell-walls. Bartnicki-Garcia \& Reyes (1964) demonstrated the presence of such complexes in Mucor rouxii which, like Rhizopus, is a member of the Mucoraceae. Hatch \& Turner (1960) showed that in the presence of systems to provide $\mathrm{NADH}_{2}$ or $\mathrm{NAPH}_{2}$, pea-seed protein disulphide reductases reduced protein disulphide linkages. Robson \&Stockley (1962), by using autoradiographic methods detected the presence of sulphydryl groups in the cell walls of many fungi.

If the above hypothesis is correct, swelling in Rhizopus spores would result from glucose-induced increased plasticity of the spore wall. Once wall plasticity is achieved, the wall stretches in response to water intake caused by the high osmotic pressure in the spores. The observations (1) that Rhizopus spores can exchange the water in the spore with heavy water in the medium and (2) that Rhizopus spores which have been incubated on the standard medium for about $3 \mathrm{hr}$, with probable dilution of their contents, become plasmolysed when placed in hypertonic salt solutions, support the view that these spores take in water by osmosis. It must be emphasised, however, that these observations prove only that water can be extruded from Rhizopus spores by osmotic methods. Systems are known in which water intake and extrusion take place by different processes, e.g. in amoeba in which water enters the organism passively but its excretion through the contractile vacuole requires respiratory energy.

Spore swelling in Rhizopus is accompanied by a considerable increase in oxygen 
uptake and an increase of about $500 \%$ in dry weight of the spores. It is inhibited by respiratory inhibitors (Table 2, and Weber \& Ogawa, 1965) and anaerobic conditions. It is thus likely that synthetic processes occur during spore swelling. Indeed, the formation of new internal structures can be demonstrated by electron microscopy during swelling. If the spores are low in nutrient content, such synthesis may account for the dependence of Rhizopus spores on exogenous nutrients for spore swelling. Anaerobic conditions and respiratory inhibitors may prevent swelling by blocking the metabolic processes necessary for the initiation of germination.

The above discussion suggests that glucose is needed for the germination of Rhizopus spores for two reasons:

(i) To generate $\mathrm{NADH}_{2}$, to reduce disulphide linkages in the spore wall and permit wall extensibility and hence osmotic swelling.

(ii) As a source of carbon and energy for the synthesis of the new inner wall of the spore which subsequently becomes the germ-tube wall.

I am indebted to Dr L. E. Hawker for supervising these investigations and for help in the preparation of the manuscript, to Dr B. F. Folkes, Dr P. Caldwell and Dr M. J. Carlile, for their interest and advice on the more biochemical aspects of the study, to Dr M. F. Madelin for helpful discussions and to Mr R. J. Hendy for instruction on the techniques of electron microscopy. I also wish to thank Professor E. W. Yemm for providing the necessary facilities for this study. This work forms part of a dissertation submitted for the degree of Doctor of Philosophy in the University of Ibadan, Nigeria, and was made possible by a grant from that University.

\section{REFERENCES}

Bartnicku-Garcia, S. \& REYEs, E. (1964). Chemistry of spore wall differentiation in Mucor rouxii. Archiv. Biochem. Biophys. 108, 125.

Crook, E. M. \& Johnston, I. R. (1962). The qualitative analysis of the cell-walls of selected species of fungi. Biochem. J. 83, 325 .

Dawson, I. M. (1949). Discussion of 'The nature of bacterial surfaces'. Symp. Soc. gen. Microbiol. 1, 119.

Ekundayo, J. A. \& Carlile, M. J. (1964). The germination of sporangiospores of Rhizopus arrhizus; spore swelling and germ-tube emergence. J. gen. Microbiol. 35, 261.

GaLe, G. R. \& McLain, H. H. (1964). Effect of thiobenzoate on cytology of Candida albicans. J. gen. Microbiol. 36, 297.

HATCh, M. D. \& Turner, J. F. (1960). A protein-disulphide reductase from pea-seeds. Biochem. J. 76, 556.

Hawker, L. E. \& Аввотт, P. Mc. V. (1963a). Fine structure of vegetative hyphae of Rhizopus. J. gen. Microbiol. 30, 444.

Hawker, L. E. \& AbBott, P. Mc. V. (1963b). An electron microscope study of maturation and germination of sporangiospores of two species of Rhizopus. J.gen. Microbiol.32, 295.

Hirano, T. \& Lindegren, C. C. (1961). Electron microscopy of mitochondria in Saccharomyces. J. Ultrastruct. Res. 5, 321.

Hirano, T. \& Lindegren, C. C. (1963). Electron microscopy of mitochondrial changes in Saccharomyces. J. Ultrastruct. Res. 8, 332.

LurT, J. H. (1956). Permanganate-a new fixative for electron microscopy. J. biophys. biochem. Cytol. 2799. 
Journal of General Microbiology, Vol. 42, No. 2

Plate 1

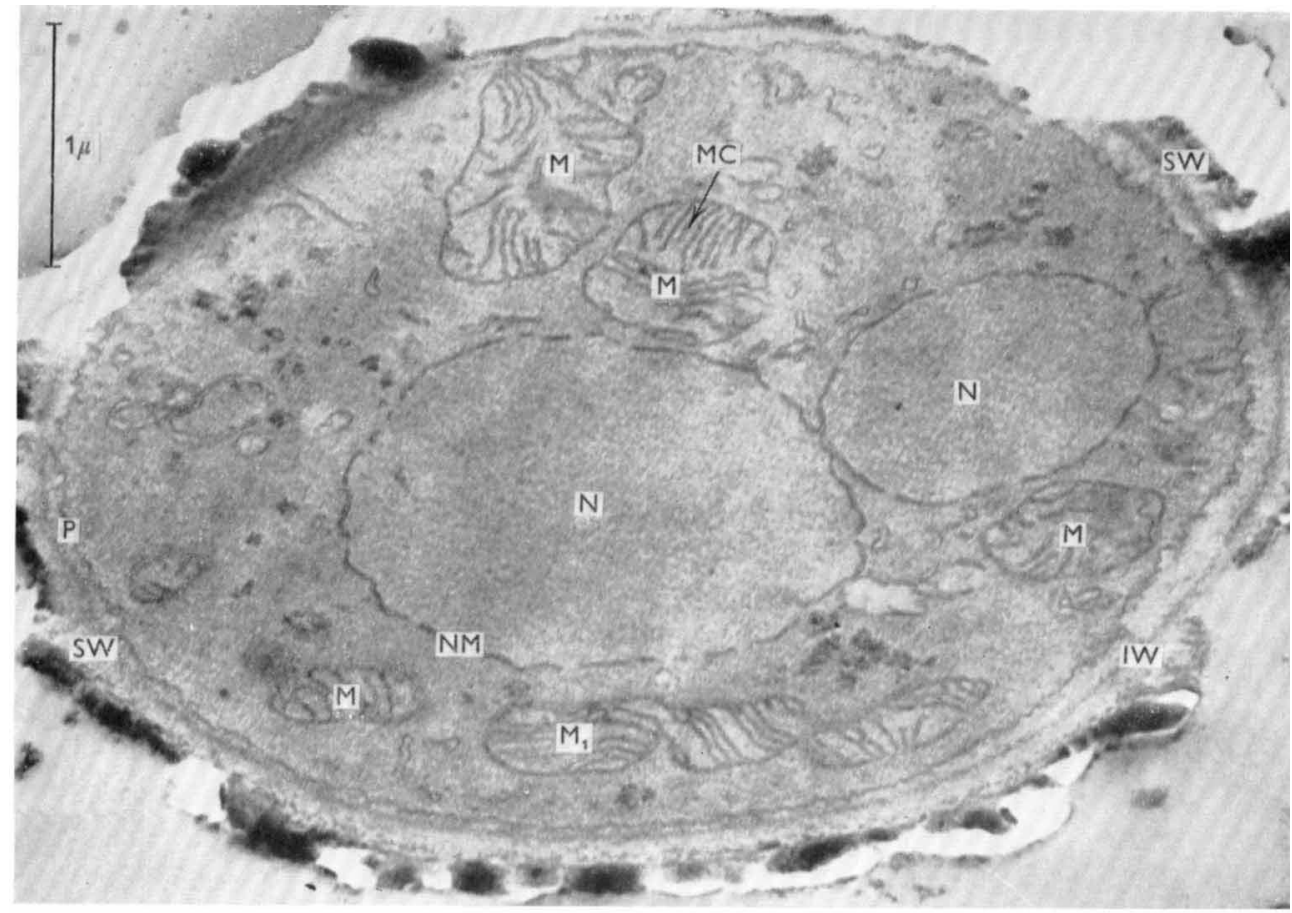

Fig. 1

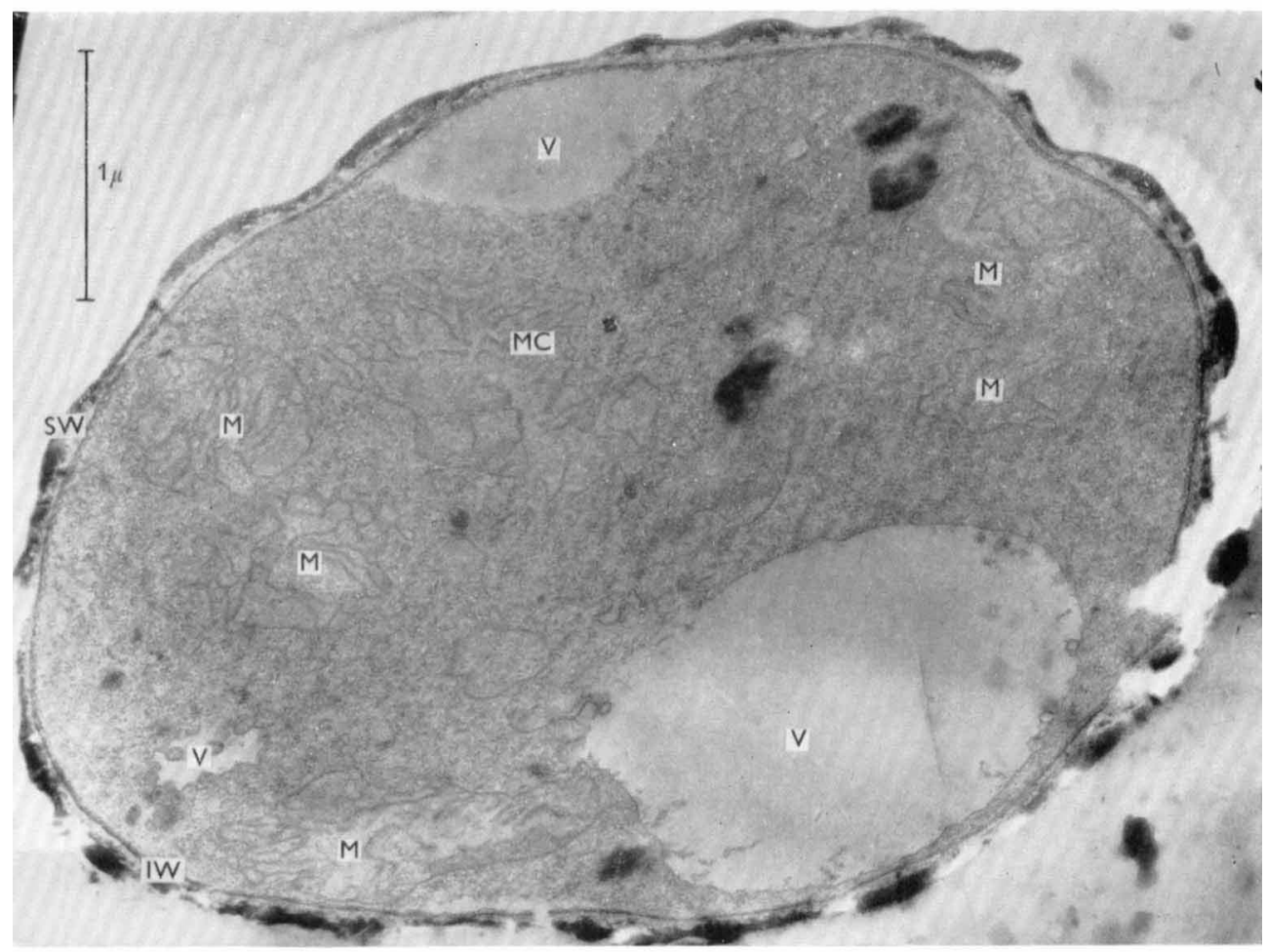

Fig. 2 
Journal of General Microbiology, Vol. 42, No. 2

Plate 2

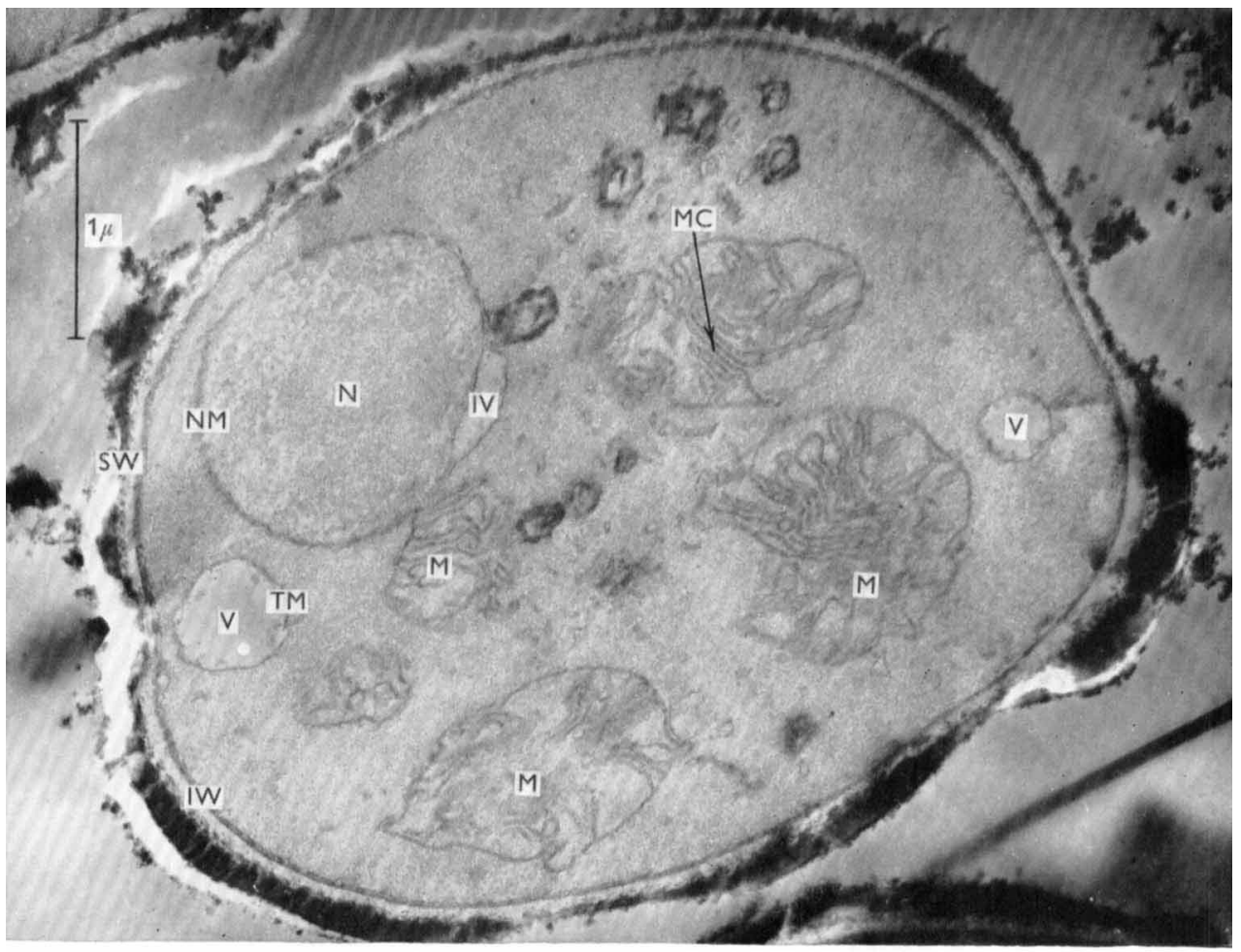

Fig. 3

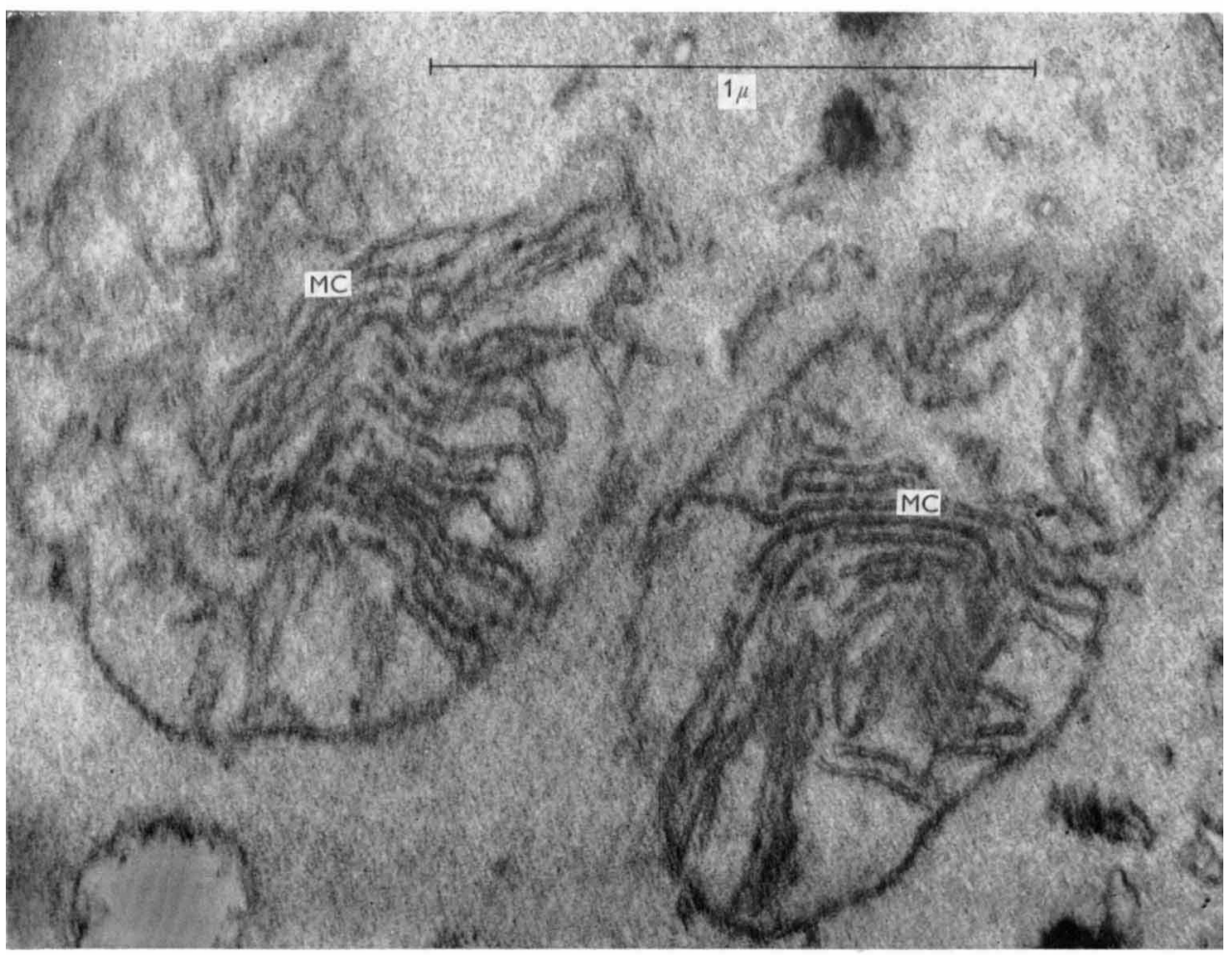

Fig. 4

J. A. FKTINDAYO 


\section{Germination of sporangiospores of Rhizopus arrhizus}

Mandels, G. R. \& Darby, R. T. (1953). A rapid cell volume assay for fungitoxicity using fungus spores. J. Bact. 65, 16.

Nickerson, W. J. (1963). Symposium on biochemical bases of morphogenesis in fungi. IV. Molecular bases of form in yeasts. Bact. Rev. 27, 305.

Robson, J. E. \& Stockley, H. M. (1962). Sulphydryl metabolism of fungi grown in submerged culture. J. gen. Microbiol. 28, 57.

Shaw, J. (1955). The permeability and structure of the cuticle of the aquatic larva of Sialis lutaria. J. exp. Biol. 32, 33.

Stannard, J. N. \& Horecker, B. L. (1948). The in vitro inhibition of cytochrome oxidase by azide and cyanide. J. biol. Chem. 172, 599.

Umbreit, W. W., BurRis, R. H. \& Stauffer, J. F. (1957). Manometric techniques. Minneapolis: Burgess Press.

Weber, D. J. \& OGaWA, J. M. (1965). The specificity of proline in the germination of spores of Rhizopus arrhizus. Phytopathology, 55, 262.

\section{EXPLANATION OF PLATES}

Electron micrographs of Rhizopus arrhizus.

SW $=$ spore wall, $\mathrm{IW}=$ Inner wall, $\mathbf{N}=$ nucleus, $\mathbf{N M}=$ nuclear membrane, $\mathbf{M}=$ mitochondria, $\mathrm{MC}=$ mitochondrial cristae, $\mathbf{P}=$ plasmalemma, $\mathrm{TM}=$ tonoplast, $\mathrm{V}=$ vacuole, $\mathrm{IV}=$ intramembranous vacuole.

\section{Plate 1}

Fig. 1. Approximately transverse section through sporangiospore incubated on standard medium for $3 \mathrm{hr}$; showing typical nuclei, development of inner wall and mitochondria (e.g. $M_{1}$ ) with constrictions along the longer axis.

Fig. 2. Section through a spore incubated on standard medium for $8 \mathrm{hr}$ followed by $5 \mathrm{hr}$ on standard medium containing $10^{-8} \mathrm{M}-\mathrm{NaN}_{3}$. Note presence of disorganized mitochondrial cristae, vacuoles have appeared in cytoplasm.

\section{Plate 2}

Fig. 3. Section through a spore incubated on standard medium for $3 \mathrm{hr}$ followed by $5 \mathrm{hr}$ in $\mathbf{N}_{\mathbf{2}}$-saturated standard medium. Note mitochondrial cristae have become disorganized and nuclear membrane split in places thus giving rise to small vacuoles between the two electrondense layers of the membrane. Features are essentially similar to those observed in spores placed under anaerobic conditions (Fig. 2).

Fig. 4. Two mitochondria from Fig. 8, enlarged. Note outer electron-dense layer of mitochondrial menbrane has disappeared in some places and mitochondrial cristae have become a collection of undulating 'plates'. 